\title{
Current Status of Research on Electrodeposited Ni-W Alloy Coating
}

\author{
Lan Zhan ${ }^{1}$, Zhen $\mathrm{Ma}^{1}$, Bing $\mathrm{Li}^{1}$, Mingzhong $\mathrm{Wu}^{1}$, Xiangge Qin ${ }^{1}$, Ninghui $\mathrm{Li}^{2}{ }^{2 *}$ \\ ${ }^{1}$ School of Materials Science and Engineering, Jiamusi University, Jiamusi, Heilongjiang, 154007, China \\ ${ }^{2}$ College of Life Science, Jiamusi University, Jiamusi, Heilongjiang, 154007, China
}

\begin{abstract}
This paper discusses the influence of $\mathrm{pH}$ value, temperature and current density on the crystalline and amorphous structure of Ni-W alloy coatings during the electroplating process. The relationship between the corrosion resistance of Ni-W alloy coating and its crystal structure is discussed. In addition, the most common types of ternary systems and composite coatings for electrodeposited Ni-W alloy coatings are introduced. The effects of element types and contents on the hardness, wear resistance, corrosion resistance and thermal stability of Ni-W alloy coatings are analyzed. Finally, the current problems and development directions of Ni-W alloy coatings are proposed.
\end{abstract}

\section{Introduction}

With the continuous development and research of alloy plating technology, there are more and more types of electrodeposited amorphous alloys, and their performance becomes more and more excellent. Since 1930, Ni-W alloy electroplating has been gradually reported. Therefore, research on the properties of nickel-tungsten alloy coatings has gradually attracted attention, and its wear resistance has also been initially applied in industry. In 1988, Omi Takashi [1] proposed the method and physical and chemical properties of electrodepositing Ni$\mathrm{W}$ alloy, and pointed out that $\mathrm{Ni}-\mathrm{W}$ amorphous coating has high hardness. Moreover, it has good corrosion resistance and good demoulding performance for glass castings. Yamasaki [2] used Ni-W alloy coating prepared by electrodeposition method and found that amorphous coating will be obtained when the content of tungsten in the coating exceeds $20 \%$. Zhu [3] studied the structure of $\mathrm{Ni}-\mathrm{W}$ alloy coating, and the results showed that: the structure of Ni-W alloy coating changes with temperature. When the tungsten content is $7-20 \mathrm{at} \%$, the coating has a face-centered cubic (FCC) nickel lattice structure; when the content is $20-40$ at $\%$, it is an amorphous structure. When the tungsten content is $40-67$ at $\%$, it is an orthorhombic structure. Nasu [4] analyzed the structure of the Ni-W alloy coating and found that the small-angle $\mathrm{X}$ ray scattering phase of the coating has an average grain size of about $2.5 \mathrm{~nm}$.

In addition, many researchers have systematically studied the electrodeposition characteristics and structure of Ni-W and Ni-W-P coatings, and have made great improvements in improving and progressing the structure and performance of the coating [5-9]. In the preparation process of pulse electrodeposition $\mathrm{Ni}-\mathrm{W}$ composite alloy coating, in order to improve the surface oxidation resistance and corrosion resistance of the alloy coating, solid particles such as $\mathrm{SiC}, \mathrm{Al}_{2} \mathrm{O}_{3}, \mathrm{ZrO}_{2}, \mathrm{WC}, \mathrm{TiC}$ and rare earth oxides are added [10-15]. And good performance and surface smoothness are obtained. Feng [16] proposed a Ni-W gradient coating and found that when the $\mathrm{W}$ mass fraction in the coating reaches $45.29 \%$, the microhardness of the gradient coating also reaches the maximum $621 \mathrm{HV}$. Others have studied the properties of nano-alloys such as Ni-W, Ni-Mo, Ni-Mo-Co and Ni-W-P, all of which have good physical and chemical properties and mechanical properties, especially in the field of MEMS, which have good application prospects [17].

\section{The structure and precipitation mechanism of Ni-W coating The influence of process conditions on electrodeposited Ni-W coating}

Because of its long-range disorder and short-range order in its atomic structure, amorphous alloys exhibit extremely excellent chemical properties, physical properties and mechanical properties [18-21] that crystalline alloys do not have. Performance [22] has become one of the important research directions in the field of materials science. Numerous research results show that when the content of tungsten in the alloy coating exceeds $44 \%$, the alloy coating has an amorphous structure [23]. Zhou [24] et al. prepared Ni-W alloy coatings with different $\mathrm{W} / \mathrm{Ni}+\mathrm{W}$ ratios by electrodeposition, and adopted XRD and EPMA analysis to determine the structure and composition of the alloy coatings. The research results show that: when $\mathrm{W} / \mathrm{W}+\mathrm{Ni}$ $\leq 0.65$ and $\mathrm{W} / \mathrm{W}+\mathrm{Ni}=0.7\left(\mathrm{Dk}\right.$ is $5 \mathrm{~A} / \mathrm{dm}^{2}$ and $\left.10 \mathrm{~A} / \mathrm{dm}^{2}\right)$ in the electroplating bath, the obtained alloy coating has a crystalline structure; When $\mathrm{W} / \mathrm{W}+\mathrm{Ni}=0.7(\mathrm{Dk}>10$

* Corresponding author: jmsdxzhanlan@163.com 
$\left.\mathrm{A} / \mathrm{dm}^{2}\right)$ and $\mathrm{W} / \mathrm{W}+\mathrm{Ni}=0.75\left(\mathrm{Dk}<15 \mathrm{~A} / \mathrm{dm}^{2}\right)$, the alloy coating shows a transition from a crystalline structure to an amorphous structure. form. When $\mathrm{W} / \mathrm{W}+\mathrm{Ni}=0.75$ $\left(\mathrm{Dk}>20 \mathrm{~A} / \mathrm{dm}^{2}\right)$ and $\mathrm{W} / \mathrm{W}+\mathrm{Ni}>0.80$, the obtained alloy coating has an amorphous structure. The structure of the crystalline Ni-W alloy coating is a substitution type solid solution in which the solute $\mathrm{W}$ occupies the position of the solvent Ni lattice point, and with the increase of the solute atom $\mathrm{W}$ content in the $\mathrm{Ni}-\mathrm{W}$ alloy coating, the degree of $\mathrm{Ni}$ lattice distortion increases. When the degree of distortion is greater than or equal to 0.022 , the structure of the alloy coating changes from a crystalline structure to an amorphous structure. At the same time, as the $\mathrm{W}$ content in the alloy coating increases, the grain refinement increases and the coating performance becomes better. The research results also show that the amorphous Ni-W alloy coating is composed of small crystal grains with a grain size of about $15-20 \AA$, and due to the scattered orientation of the small crystal grains, it exhibits shortrange order and long-range disorder structure.

Alloy coatings with different compositions can be deposited by adjusting the different ratios of $\mathrm{Ni}-\mathrm{W}$ in the plating solution. Ni-W crystalline alloy is a solid solution structure with $\mathrm{Ni}$ as the solvent and $\mathrm{W}$ as the solute. As the concentration of $\mathrm{Na}_{2} \mathrm{WO}_{4}$ in the plating solution increases, the plating layer The content of tungsten also increases. The coating structure gradually transitions from the crystalline state to the amorphous state. In the structure of the alloy, the atomic arrangement has no translational periodicity, and there are no crystal defects such as dislocations, crystals, and grain boundaries. Compared with crystalline alloys, Better corrosion resistance and wear resistance.

\section{The influence of process conditions on electrodeposited $\mathrm{Ni}-\mathrm{W}$ coating}

The process conditions of electroplating include current density, $\mathrm{pH}$ value and temperature, which have a great influence on the formation process and performance of the coating.

\subsection{The influence of the $\mathrm{pH}$ value of the electroplating solution}

The $\mathrm{pH}$ value reflects the concentration of $\mathrm{H}^{+}$in the electroplating solution. The concentration of $\mathrm{H}^{+}$will directly affect the hydrogen evolution reaction on the cathode. When the $\mathrm{pH}$ is too high, the $\mathrm{H}^{+}$concentration of the cathode will be too high. After a reduction reaction, a large amount of $\mathrm{H}_{2}$ will be produced on the coating, resulting in the coating. Hydrogen holes appear on the surface, which affects the quality of the coating. Lin et al. [25] studied the influence of $\mathrm{pH}$ on the composition and structure of the coating. The results show that the $\mathrm{pH}$ value of the electroplating solution directly affects the composition and stability of complex ions. When the acidity is too high $(\mathrm{pH} \leq 3)$, citric acid is easy to decompose and the ability to complex tungsten is weak, resulting in the dominant nickel deposition on the cathode. When the acidity is too low $(\mathrm{pH} \geq 9)$, the nickel salt is hydrolyzed. Moreover, if the $\mathrm{pH}$ value of the electroplating solution is too high, the nickel-tungsten alloy coating becomes brittle and blisters occur. If the $\mathrm{pH}$ value is too low, the coating becomes darker. The Laser Fusion Research Center of China Academy of Engineering Physics [26] found through experiments that if the $\mathrm{pH}$ value is too high $(\mathrm{pH} \geq 9)$, the coating becomes brittle and easy to foam. The $\mathrm{pH}$ value is too low $(\mathrm{pH} \leq 5)$, and the coating is dull. If the $\mathrm{pH}$ value is too high or too low, the coatings are all crystalline structures, the $\mathrm{W}$ content is low, and the corrosion resistance is poor. The $\mathrm{pH}$ value is in the range of 6.5 to 7.5 , it is easy to obtain the amorphous $\mathrm{Ni}$ $\mathrm{W}$ alloy coating with high $\mathrm{W}$ content, and the corrosion resistance is better.

\subsection{The influence of temperature on coating quality}

During the electrodeposition process, generally as the reaction temperature increases, the thermal movement of the metal ions and solid particles in the electroplating solution becomes intense. The viscosity of the electroplating solution decreases, and the transfer and transport speed of ions increases. In addition, the solid particles adsorbed in the metal increase correspondingly, and the deposition amount of the electrodeposited solid particles in the coating increases. However, if the temperature is too high, the stability of the electroplating solution system will be damaged, resulting in a decrease in the adsorption capacity of solid ions and a decrease in the efficiency of electrodeposition. Studies have found that when the electrodeposition temperature is greater than $50{ }^{\circ} \mathrm{C}$, the Ni-W coating obtained is amorphous, and the tungsten content of the coating is greater than $44 \%$. When the temperature is lower than $40{ }^{\circ} \mathrm{C}$, only crystalline coating can be obtained [24]. However, the latest research shows that it is easiest to deposit amorphous $\mathrm{Ni}-\mathrm{W}$ coatings at $55-65^{\circ} \mathrm{C}[26]$. For Ni-W-P coatings to start to transform from crystalline to amorphous, the temperature must be increased to $80{ }^{\circ} \mathrm{C}$, then an amorphous Ni-W-P coating with better corrosion resistance can be obtained [27]. Therefore, for different tungsten alloy systems, the electrodeposition temperature at which the coating changes from a crystalline state to an amorphous state is different, and the temperature at which an amorphous coating is most easily deposited is also different.

\subsection{The influence of current density on the composition and structure of the coating}

Since the increase in current density is beneficial to the cathodic polarization of $\mathrm{W}$, the content of $\mathrm{W}$ in the $\mathrm{Ni}-\mathrm{W}$ coating increases. On the contrary, $\mathrm{Ni}$ ions are preferentially deposited. According to the diffusion theory, increasing the current density helps increase the deposition rate of metals with negative potentials, and also increases the $\mathrm{W}$ content in the coating. In addition, the greater the current density, the enhanced cathode polarization, and the finer the coating crystallization. But when the current density is too large, hydrogen escapes from the surface, the coating is thin and rough, and the 
corners are black. Therefore, in various systems of tungsten-based alloy electrodeposition, there is a most suitable current density range. The current density has a certain effect on the structure and composition of the coating. Zhou et al. [28] found that as the current density increases, the tungsten content in the coating gradually increases. When the current density is $15 \mathrm{~A} / \mathrm{dm}^{2}$, the tungsten content of the coating is $39.5 \%$. When the current density is $20 \mathrm{~A} / \mathrm{dm}^{2}$, the tungsten content is $46 \%$, and the coating structure changes from crystalline to amorphous.

\section{Development of $\mathrm{Ni}-\mathrm{W}$ Composite Coating}

At present, there are many kinds of electrodeposited tungsten alloys, in addition to binary system coatings, it also includes ternary system tungsten alloy coatings and Ni-W composite coatings.

\subsection{Ni-W ternary alloy coating}

\subsubsection{Ni-W-P ternary alloy coating}

In order to improve the corrosion resistance of the coating, $\mathrm{P}$ is added to the Ni-W amorphous coating to become a NiW-P ternary alloy coating. Especially in acidic solutions, Ni-W-P ternary alloy coatings have better corrosion resistance than Ni-W and Ni-P amorphous coatings [29]. The deposition of phosphorus in the Ni-W-P ternary alloy coating is mainly affected by the bath temperature and $\mathrm{pH}$ value [30]. When the temperature is higher than $80^{\circ} \mathrm{C}$, the coating has an amorphous structure. Under various $\mathrm{pH}$ values, the sum of $\mathrm{W}$ and $\mathrm{P}$ content in the coating is higher than $40 \%$, and the coating has an amorphous structure. If the Ni-W-P amorphous alloy coating is applied to the continuous casting mold, the quality and service life of the continuous casting billet can be improved [31].

\subsubsection{Ni-W-B ternary alloy coating}

Ni-W-B ternary alloy coating, which are formed by adding boric acid to the Ni-W alloy coating bath, can significantly improve the corrosion resistance, wear resistance, hardness and other properties of the coating $[32,33]$. When the content of boron in the Ni-W-B ternary alloy coating is $1 \%$, and the content of tungsten is $30 \%$ to $50 \%$, the coating structure is amorphous. The microhardness of the Ni-W-B ternary alloy coating will increase with the optimization of the heat treatment process and the increase in the composition of tungsten in the coating [34].

\subsection{Ni-W based composite coating}

The Ni-W-based composite coating is formed by using electrodeposition technology to make insoluble solid particles evenly and uniformly incorporated in the nickeltungsten alloy coating. The included particles mainly include insoluble solid particles such as silicon carbide, zirconium dioxide, and aluminum oxide. Thereby forming a composite coating.

\subsubsection{Ni-W-SiC composite coating}

By improving the performance of the traditional $\mathrm{Ni}-\mathrm{W}$ alloy coating, the Ni-W-SiC composite coating is obtained by adding solid silicon carbide particles to the nickeltungsten plating solution. Improve the hardness, wear resistance and corrosion resistance of the coating by controlling the content of silicon carbide and the heat treatment process.

\subsubsection{Ni-W-P-SiC composite coating}

The Ni-W-P-SiC composite coating is obtained by adding solid silicon carbide particles into the Ni-W-P alloy coating bath. The structure of the Ni-W-P-SiC composite coating is mainly related to the temperature of the heat treatment process. When the heat treatment temperature is below $300{ }^{\circ} \mathrm{C}$, the Ni-W-P-SiC composite coating has an amorphous structure. When the heat treatment temperature is higher than $400{ }^{\circ} \mathrm{C}$, the Ni-W-P-SiC composite coating begins to transform from an amorphous structure to a crystalline structure. At the same time, the mechanical properties, corrosion resistance and wear resistance of the Ni-W-P-SiC composite coating will become better with the transformation of the crystalline structure [35].

\subsubsection{Ni-W-ZrO2 composite coating}

The $\mathrm{Ni}-\mathrm{W}-\mathrm{ZrO}_{2}$ composite coating is obtained by adding solid particles of zirconium dioxide to the Ni-W alloy coating bath. The structure of the $\mathrm{Ni}-\mathrm{W}-\mathrm{ZrO}_{2}$ composite coating is mainly related to the content of solid particles and the content of tungsten. When the content of solid particles of zirconium dioxide is in the range of $10.0 \%$ to $36.2 \%$, and the content of tungsten is in the range of $47.5 \%$ to $53.1 \%$, the structure of the $\mathrm{Ni}-\mathrm{W}-\mathrm{ZrO}_{2}$ composite coating is amorphous. The microhardness, corrosion resistance and wear resistance of the Ni-W-ZrO $\mathrm{Zr}_{2}$ composite coating are closely related to the heat treatment process and the solid particle content of zirconium dioxide [36].

\subsubsection{Ni-W-Al2 $\mathrm{O}_{3}$ composite coating}

The Ni-W- $\mathrm{Al}_{2} \mathrm{O}_{3}$ composite coating obtained by adding solid particles of aluminum oxide to the $\mathrm{Ni}-\mathrm{W}$ alloy coating bath possesses a crystalline structure. $\mathrm{Al}_{2} \mathrm{O}_{3}$ effectively improves the electrodeposition efficiency, microhardness, thickness, surface quality and wear resistance of the coating [13]. In addition, the microhardness of the $\mathrm{Ni}-\mathrm{W}-\mathrm{Al}_{2} \mathrm{O}_{3}$ composite coating is related to the heat treatment temperature.

\section{Conclusion}

$\mathrm{Ni}-\mathrm{W}$ alloy has been widely researched and applied because of its unique tribological, magnetic, optical, 
electrical and electro-corrosion properties. In particular, the rapid development of nanotechnology has promoted the research of electrodeposited nanocomposite coatings to a higher level. However, the current depth and breadth of research on Ni-W alloys are far from enough, and both technological and theoretical aspects are very weak. For example, key issues such as the co-deposition mechanism of nano-composite coating particles and metal ions have not been satisfactorily resolved. Secondly, although the Ni-W multiple composite coating has achieved certain results in research, the mechanism of improving the corrosion resistance of alloy coatings needs to be further studied. It is of great significance that strengthen the research on the process and mechanism of electrodeposition of nickel-tungsten alloy to the development and practical application of electrodeposition technology and even the entire field of surface engineering. In the future, the numerical simulation of electrodeposition process will play an important role in mechanism research.

\section{Acknowledgement}

Authors wishing to acknowledge financial support from University Nursing Program for Young Scholars with Creative Talents in Heilongjiang Province of China (Grant No. UNPYSCT-2018116).

\section{References}

1. O. Takashi, Met. Surf. Technol 39, 809-812 (1998)

2. T. Yamasaki, Proceedings of International Symposium on Amorphous and Nanocrystalline Materials (Jap. Soc. Promo. Sci., A. Inoue, 2000)

3. L. Zhu, O. Younes, Appl. Surf. Sci., 200, 1-14 (2002)

4. T. Nasu, M. Sakurai et al, Mat. Sci. Eng. A, 375-377, 163-170 (2004)

5. S.W. Yao, C. Wang, H.T. Guo et al., Mat. Protect., 26, 91 (1993)

6. L. Chen, N. Li, M.X. Zhang, Solid State Chemistry, 249, 9-14(2017)

7. B.Y. Wang, J. Yu, Q.W. Niu, Z.L. Li, Hot Working Technology, 20, 93-95 (2014)

8. M. Ahmadi, M.J. Guinel, Microscopy and Microanalysis, 18, 1694 - 1695 (2012)

9. S.H. Wang, H.P. Zhang, H. Du et al, Applied Chemical Industry, 44, 732-735 (2015)

10. A. AlZahrani, Y. Alhamed, L. Petrov et al., Journal of Solid State Electrochemistry, 7, (2014)

11. F.B. Wang, Y. Li, Y.C. Wu, X. Shu, L.P. Wang, Plating and Environmental Protection, 29, 9-12 (2009)

12. X.H. Zhang, Y.S. Chen, H. Chen et al., World Nonferrous Metals, 12, 33-35 (2009)

13. M.X. Liu, Z. Huang, X.R. Ren, X.H. Zhang, H. Chen, Rare Metals, 41, 665-671(2017)

14. M.H. Allahyarzadeh, M. Aliofkhazraei, A.R. Sabour Rouhaghdam, V.Torabinejad, J.Alloy. Compd., 666,
217-226 (2016)

15. X.J. Liu, W.C. Sun, Y.R. Dong, M. Ma, Y.G. Zhang, F.Yang, Y.Y. Ruan, T. Indian. Metal., 72, 1187-1199 (2019)

16. P. Feng, Journal of Tribology, 37, 305-309 (2017)

17. S. Costovici, A.C. Manea, T. Visan, L. Anicai, Elcetrochim. Acta, 207, 97-211 (2016)

18. F.Z. Yang, Z.H. Ma, L. Huang, S.K. Xu, S.M. Zhou, Chinese Journal of Chemistry, 24, 114-118 (2006)

19. H. Wang, R. Liu, F.J. Cheng, Y. Cao, G.F. Ding, X.L. Zhao, Microelectron. Eng., 87, 1901-1906 (2010)

20. Y.F. Lan, F. Tao, Q.L. Li, Corrosion and protection, 38, 96-100 (2017)

21. M.M.V. Parente, O.R. Mattos, S.L. Díaz, P.L. Neto, F.J. Fabri Miranda, J. Appl. Electrochem., 31, 677683 (2001)

22. M.P.M. Kaninski, D.P. Saponjic, I.M. Perovic, A.D. Maksic, V.M. Nikolic, Appl. Catal. A-GEn, 405, 2935 (2011)

23. T. Yamasaki, P. SchloBmchor, Nanostructured Materials, 10, 387 (1998)

24. W.Q. Zhou, H.T. Guo, S.W. Yao, Surface Technology, 26, 6-9 (1997)

25. W.X. Lin, D.L. Chen et al., Chemistry World, 7, 295 (1991)

26. X.B. Wan, L. Zhang et al., Material Protection, 12, 23-26 (2006)

27. S.G. Jia, B.Y. Jiang et al., Surface Technology, 5, 1922 (1999)

28. W.Q. Zhou, Electroplating \& Coating, 15, 18-19 (1996)

29. S.W. Yao, Z.L. Xiao Ruo, Material Protection, 27, 9$11(1994)$

30. L. Zhang, Y.W. Yao, W. Wu et al., Tianjin Chemical Industry, 4, 9-11 (2006)

31. C.Y. Zhu, J.P. Rao, Journal of Wuhan University of Science and Technology, 30, 364-367 (2007)

32. L.Q. Zhu, W.P. Li, Electroplating \& Painting, 23, 1015 (2004)

33. R.A.C. Santana, S. Prasad, Journal of Applied Electrochemistry, 36, 105-113 (2006)

34. C. Yu, West China Science and Technology, 31, 2 (2006)

35. L. Benea, F. Wenger, P. Ponthiaux et al., Wear, 266, 398-405 (2009)

36. X. Shu, Y. Li, Y.C. Wu, X.M. Huang, Y.C. Zheng, Journal of Composite Materials, 6, 116-120 (2006) 